\title{
الاتجاه المقاصدي في تفسير ابن عاشور
}

\section{سامر عبدالرمن رشواين}

يعرف "الاتجاه" بأنه بجموعة المبادئ والأفكار المحدة التي يربطها إطار نظري، وقدف إلى غاية محدة.1 أما "المنهج" فهو بموعة الوسائل والآليات الفكرية الموظفة لاحتواء أفكار التحاه ما وتحقيق غايته؟.

وتنبع أهية هذا التمييز بالنسبة للتفسير خصوصاً من تطورات العصر الحديث، وما فرضته من مناهج متنوعة في تناول النص القرآني، وأساليب وأشكال فنية في تفسير الآيات القرآنية، تختلف عن الطريقة التقليدية التي التزمها المفسرون طوال عصورهم السابقة. هذا فضلاً عن الضرورة المنهجية التي تفرض مثل هذا التفريق.

وهكذا يتحدد "الاتجاه التفسيري" بمجموعة الآراء والأفكار والنظرات والمباحث التي تشيع في تفسير ما، وتكون غالبة على ما سواها، ويكمها إطار نظري أو فكري كلية تعكس بصدق مصدر الثقافة التي تأثر لها صاحب التفسير

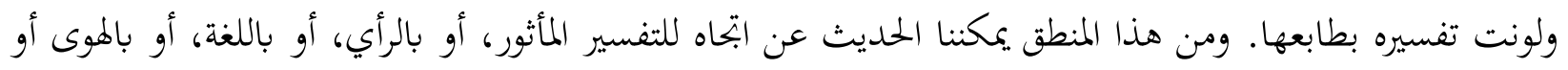

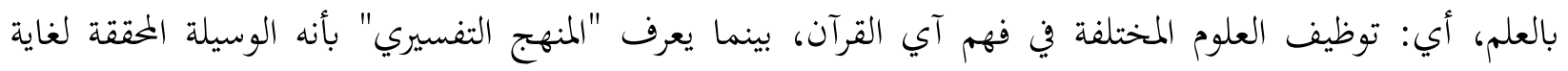
الابتحاه التفسيري، والوعاء الذي يمتوي أفكار هذا الابتحاه التفسيري أو ذاك. مثل المنهج التقليدي أو الموضوعي. ولا بد من أن نشير إلى أن هذا التقابل بين الاتحاهات ليس حاداً. فالاتحاه الواحد في التفسير على الرغم من

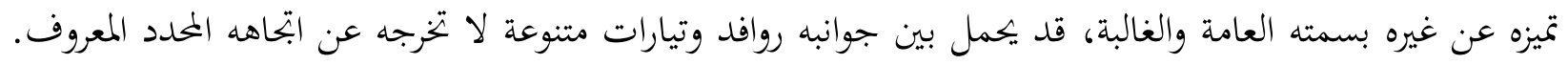

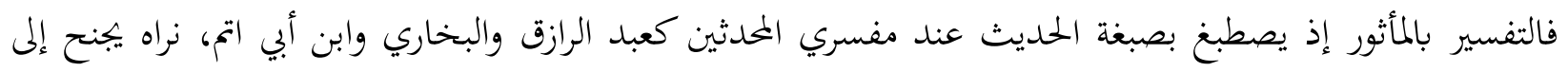
جانب اللغة عند مفسر كالبغوى، ويتلون بلون الحديث والفقه معاً عند ابن كثيرُ.

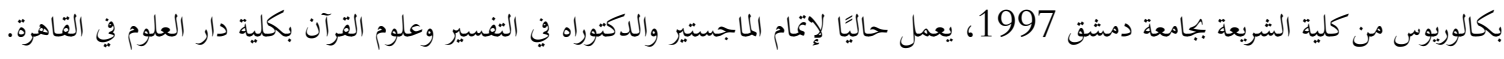

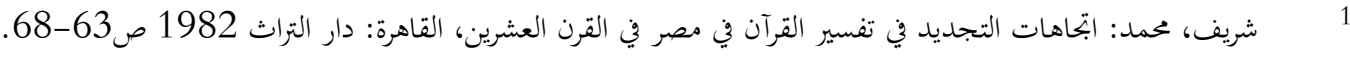

$$
\begin{aligned}
& 2
\end{aligned}
$$


كما أن أي اتجاه تفسيري مهما تنوع أو اختلف، يمكن أن يتحقق من خلال أحد المناهج التفسيرية التقليدية القديمة، أو الموضوعية، أو الموضوعية التقليدية، أو المقال التفسيري. نخلص من هذا كله إلى أن منظور تناوله لتفسير (التحرير والتنوير) هي مبادئه وأفكاره العامة المحددة لأهدافه وغاياته التي تسري وتتغلغل في ثناياه.

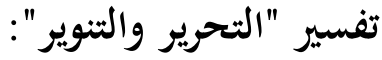

إذا كان تفسير المنار من أهم الكتابات التفسيرية في الشرق العربي في القرن العشرين فإن تفسير ابن عاشور "التحرير والتنوير" يهظى بالمكانة ذاتها في المغرب العربي. ولعل ما سيأتي يوضح الأسباب الموضوعية التي أكسبت هذا التفسير تلك الأهمية والمكانة السامقة.

لقد سنح لمحمد الطاهر بن عاشور أن يشرع في تصنيف تفسيره بعد أن انتقل من خطة القضا إلى خطة الفتيا سنة (1923-1341) كما يذكر في خطبة تفسيره3. "فأقدم على هذا المهم إقدام الشجاع على وادي السباع" وأمضى في تأليفه ما يربو على تسع وثلاثين سنة، تقلب فيها بين كثير من الوظائف و أنجز كثيراً من الكتب والتصانيف، فكان تمام التفسير في عصر 12 رجب سنة 1380هـ (1961) كما يحدد ابن عاشور -بدقة- في هاية التفسير. ويلحظ أن هذه المدة الطويلة قد عاصرت تغيرات وتحولات كبيرة في المجتمع التونسي، لا سيما الاستقلال والتحديات التي واجهتها الحركة الإصلاحية، الأمر الذي يتوقع أن تنعكس آثاره على تفسيره، ولكنني لم استطع أن أضع يدي بدقة على هذه الآثار، ولعلها تحتاج إلى دراسة أوسع وتحر أدق.

يقع تفسير "التحرير والتنوير" في ثلاثين جزءاً، طبعت طبعات مختلفة وكثيرة، ولم أقف -في ما وقع بين يدي من مصادر- على تحديد لتاريخ الطبعة الاولى من هذا التفسير. ويبدو أن هذه البسطة في الحجم قد أكسبته صفة الموسوعة العلمية الشاملة التي تدل على سعة علم صاحبه وتنوع مناحي ثقافته، كما تدل على دأب جاد وعزيمة صادقة على إتمام هذا العمل المستفيض. وهذا ما عجز عنه كثير من علماء هذا الزمان، الذين قضوا خبهم قبل أن يتموا تفاسيرهم، أو آثروا كتابة تفاسير موجزة صغيرة.

$$
3
$$


يفتتح ابن عاشور تفسيره بمقدمات عشر ${ }^{4}$ يرى أها ستكون عوناً للباحث في التفسير، وستغنيه عن معاد كثير، وتشبه أن تكون مقدمات في علم أصول التفسير وبعض علوم القرآن: كأسباب الترول، والقراءات والقصص، والإعجاز القرآي.

ويلحظ في هذه المقدمات أن الهدف منها لم يكن تفصيل القول في هذه الموضوعات واستقصائه بقدر ما كان الهدف إعطاء لمحة موجزة عنها، وتحديد طريقته، ومنهجه في تفسير القرآن وتأويله، وموقفه من بعض القضايا الخلافية بين المفسرين. من هنا تكتسب هذه المقدمات أهمية كبيرة في تحديد طريقة ابن عاشور، ومنهجه، واتجاهه التفسيري كما بحلى في ثنايا تفسيره، كما سنرى لاحقاً. يشرع ابن عاشور بعد هذه المقدمات في تفسير سور القرآن الكريم سورة سورة، وآية آية، طبقاً للأسلوب الذي درج عليه المفسرون القدامى في تفسير القرآن. وقد درج في تفسيره لأي سورة على تقديم لمحة عن اسم السورة، وسبب تسميتها بهذا الاسم، وعن مكان نزوها، وزمانه، وموقعها من القرآن، وعدد آياها مع إيراد الآراء المختلفة في ذلك كله. بعد هذه المقدمة يخصص ابن عاشور فقرة خاصة مستقلة يعرض فيها "أغراض السورة"، وسنرى أن لهذه الفقرة أهمية بالغة في ابتحاهه التفسيري. تم يبدأ بعد هذا في التفسير آيات السورة آية تلو أخرى حتى تنتهي.

\section{المبحث الأول: الاتجاه المقاصدي في تفسير ابن عاشور: (المستوى التنظيري):}

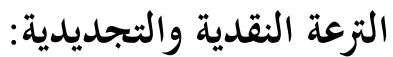

قد لا تستطيع نظرة عجلى في تفسير ابن عاشور أن تعطينا حكماً موضوعياً مناسباً عنه. حيث توحي مثل هذه النظرة أنه من ذلك الطرز التقليدي من التفاسير الحاوية من كل فن وعلم والمشتملة على كل مذهب وقول، من غير ما انفرد بطريقة خاصة في التفسير والتأويل ولا استقلال برأي أو منهج أو دليل. ولعل الذي ساعد على هذا التوهم أسلوب الطاهر وطريقة عرضه للتفسير.

4 4 شر هذه المقدمات تباعاً في المجلة الزيتونية التي كان صدورها عام 1311 هـ/ 1935م، ثم نشرها في كتاب مستقل بعنوان "مقدمات التفسير". وتمتد هذه المقدمات على نخو 130 صفحة في التفسير.

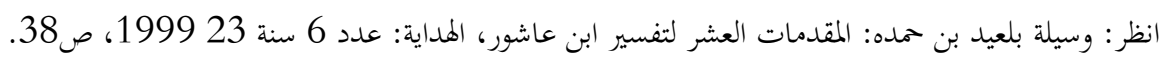


ولكن النظر المدقق في مقدمات تفسيره وتضاعيفه يدفع ذاك التوهم وينقض تلك الفكرة المتسرعة، ويثبت أن لابن عاشور ابتحاهه المميز وطريقته الخاصة في تفسير القرآن وتأويله، ويؤكد بأنه انخراط في الحركة الإصلاحية والتجديدية التي نشأ بين أحضاها فكراً وتطبيقاً، مع الانفراد بطريقة خاصة تميزه عن جميع أقرانه ونظرائه من التجديديين والإصلاحيين. فإننا لا نكاد نتجاوز خطبة الكتاب حتى نسمع ابن عاشور يقول: "فجعلت حقاً عليّ أن أبدي في تفسير القرآن الكريم نكتاً لم أر من سبقني إليها، وأن أقف موقف الحكم بين طوائف المفسرين تارة لها وآونة

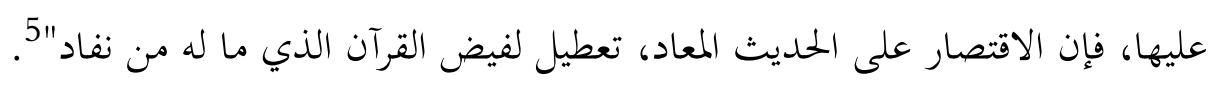

فابن عاشور ملتزم منذ اللحظة الأولى أن يقدم لنا الجديد مما لم يفطن له الأقدمون، وأن يقف من تراثهم موقف الناقد المحقق لا المقلد المتبع. بل إنه يفصّل كلامه السابق قائلاً:" ولقد رأيت الناس حول كلام الأقدمين أحد رجلين: رجل معتكف فيما شاده الأقدمون، وآخر آخذ بمعوله فيهدم ما مضت عليه القرون، وفي كلتا الحالتين ضر كثير، وهنالك حالة أخرى ينجبر بها الجناح الكسير، وهي أن نعمد إلى ما أشاده الأقدمون فنهذبه ونزيده، وحاشا أن ننقصه أو نبيده، علماً بأن غَمط فضلهم كفران للنعمة، وجحد مزايا سلفها ليس من حميد خصال الأمة". إذن فنحن أمام نظرة نقدية بتحيدية، لا ترضى بجمع القديم واستقصائه، بل تتطلع نحو فرز هذا التراث وقذذيبه، ومن ثم الإضافة عليه وزيادته من واقع "فيض القرآن الذي ما له من نفاد". "فالتفاسير وإن كانت كثيرة فإنكك لا بحد الكثير منها إلا عالة على كلام سابق بحيث لاحظً لمؤلفه إلا الجمع على تفاوت بين اختصار وتطويل"6. لذا لا يختار ابن عاشور من التفاسير إلا عيوها بل إن ابن عاشور يرى أن أهم أسباب تأخر "علم التفسير"هو الولع بالتوقيف والنقل، اتقاء الغلط الذي عظموا أمره في القرآن" مما نتج عنه أن أصبح الناس يغتفرون في التفسير النقل ولو كان ضعيفاً أو كاذباً، ويتقون الرأي ولو كان صواباً حقيقياً، لأغم توهموا أن ما 
خالف النقل عن السابقين إخراج للقرآن عما أراد الله به"7. وبسبب ترسخ هذه النظرة آل الأمر بالتفسير إلى أن أصبح " تسجيلاً يقيد به فهم القرآن، ويضيق به معناه"

ولا أدل على هذه الرؤية النقدية التجديدية المتجذرة عند ابن عاشور من عنوان تفسيره الأصلي وهو " تحرير المعنى السديد، وتنوير العقل الجديد، من تفسير الكتاب المجيد"، الذي اختصره فيما بعد ليصبح" التحرير والتنوير من التفسير". و وإذا كان ابن عاشور من المؤمنين بضرورة التجديد والمتطلعين للضرب فيه بسهم، فكيف يحدد ابن عاشور مضمون هذا التجديد في التفسير وطريقته؟ بعبارة أخرى، ما جوهر وما جماع الأفكار والرؤى النقدية والتجديدية التي يطرحها ابن عاشور؟! قد لا تكفينا - لتقديم إجابة دقيقة متكاملة - مطالعة تفسير ابن عاشور بمقدماته العشر. بل يلزمنا لفهم طريقة ابن عاشور ونظريته الإطلاع على مختلف نتاجاته الفكرية وخلبفته الاجتماعية والثقافية، الأمر الذي سيوحي لنا بالكثير، وسيفسر لنا أموراً كثيرة ما كنا نعلم أهميتها لديه ومكانتها لولا ذلك. وقد ذكرنا طرفاً من حياته وكتاباته فيما سبق.

انطلاقاً من ذلك يككن القول إن الخيط الذي يسلك فكر ابن عاشور في نسق واحد، أو "المفهوم المفتاحي" الذي يتخلل في ثنايا كتاباته هو مفهوم "المقاصد". فقلما يعالج ابن عاشور موضوعاً- ايّ موضوع كان -هي مقالة أو كتاب دون أن يرد لمفهوم "المقاصد" ذكر، أو يكون له دور في بناء فكرهوتطويرها حول ذلك الموضوع. بل يمكن القول -بقليل من المجازفة- إن مفهوم "المقاصد" هو من أكثر المفاهيم والمصطلحات توارداً وتواتراً في نصوص ابن عاشور. فإلام نرجع تفسير هذه الظاهرة؟!

يبدو أن الأمر لا يحتاج كثير تحليل وعناء لفهم ذلك. فالناظر في الخلفية العلمية التي نشأ عليها ابن عاشور يلحظ أنه ينتمي إلى المدرسة المالكية المغربية، ومعلوم ما لمذه المدرسة من تميز وملامح خاصة تختلف عن مالكية

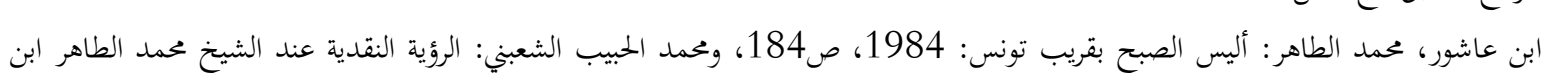

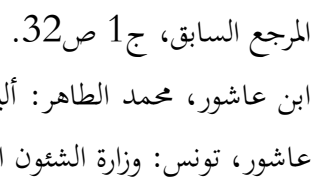

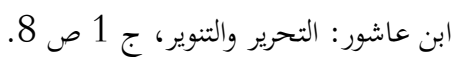


المشرق، لا سيما في مجال " مقاصد الشريعة" التي بلغ فيها الشاطبي شأواً عظيماً. وهذه " الترعة المقاصدية" وإن خبت لفترة من الزمن، لكنها ظلت كامنة بالقوة، منتظرة الحركات الإصلاحية التي بدأت بشائرها في المغرب العربي في النصف الثاني من القرن التاسع عشر حتى تبعث وتحيا من جديد. وهكذا يطبع" الموافقات" أول طبعة له في تونس سنة 1302هـ-1884م، ويعزى هذا الدور تاريخياً إلى خير الدين التونسي 10، ويكتب علال الفاسي كتاباً يتعرض فيه لمقاصد الشريعة على نحو موجز، وإذا أضفنا إلى ذلك أن مدرسة الإصلاح المشرقية-بزعامة الأفغاني وعبده-قد أولت اهتماماً بالغاً بمقاصد الشريعة، حتى نقل عن الإمام محمد عبده تنبيه وتوصيته الملحمة بأهمية كتاب " الموافقات وضرورة نشره والاستفادة منه. 11

في ظل هذا الوضع لم يكن من ابن عاشور إلا أن انطبع هذا الاهتمام، وتشرب هذا التوجه، فأخرج لنا أول مؤلف مستقل متكامل في "مقاصد الشريعة الإسلامية" في العصر الحديث، حتى إنه لفرط حماسته كان أول من دعى إلى إنشاء علم مستقل يدعى "علم مقاصد الشريعة". وقد وضع ابن عاشور في كتابه هذا خلاصة نظريته المقاصدية وزبدها على نحو دقيق ومنهجي، حتى أنشأ مدرسة أو ابتحاًاً مقاصدياً كاملاً في المغرب العربي.

فإذا كان الأمر على هذا النحو فلا غرو أن يندرج تفسيره أيضاً ضمن هذا النسق الفكري، ويتشح بهذه الطريقة والنظرية المقاصدية، لتسري في حنايا تفسيره وتبرز بشكل تطبيقي عملي. وهذا ما سنحاول تلمسه وتتبعه في ما يأتي:

\section{طبيعة الاتجاه المقاصدي:}

يكرس ابن عاشور منذ خطبة تفسيره مفهوماً للقرآن الكريم ذا ثلاث شعب:

فالقرآن هو: الجامع لمصالح الدنيا والدين. والحاوي لكليات العلوم ومعاقد استنباطها. والآخذ قوس البلاغة من

محل نياطها 12.

10 الحسيني، إسماعيل، نظرية المقاصد عند الطاهر بن عاشور، القاهرة: المعهد العلمي للفكر الإسلامي 1995، ص 18

$$
\begin{aligned}
& 11 \\
& 12
\end{aligned}
$$


هذا التحديد وإن جاء على نحو عرضي في سياق خطبة ابن عاشور، إلا أن له بالغ الأثر والأهمية في التعريف بتفسيره وطريقته ومنهجه، كما سترى لاحقاً.

يفرد ابن عاشور مقدمة بالغة الأهمية يمدد فيها غرض المفسر من التفسير ويتعرض فيها لمقاصد القرآن والعلاقة بين هذين الأمرين. يبدأ ابن عاشور حديثه عن مقاصد القرآن فيتناولها من زاويتين: يحدد في الأولى المقصد الأعلى من القرآن، وفي الثانية المقاصد الأصلية التي جاء القرآن لبياها.

أما المقصد الأعلى من القرآن الكريم فهو كما يحدده ابن عاشور: " صلاح الأحوال الفردية والجماعية والعمرانية" وتفصيل هذا هو أن: "الصلاح الفردي يعتمد تذذيب النفس وتزكيتها، ورأس الأمر فيه صلاح الاعتقاد لأن الاعتقاد مصدر الآداب والتفكير، تم صلاح السريرة الخاصة، وهي العبادات الظاهرة كالصلاة، والباطنة كالتخلق بترك الحسد والحقد والكبر". وأما الصلاح الجماعي بصلاح أجزائه، ومن شيء زائد على ذلك وهو ضبط تصرف الناس بعضهم مع بعض على وجه يعصمهم من مزاحمة الشهوات ومواثبة القوى النفسانية. وهذا أوسع من ذلك، إذ هو حفظ نظام العالم الإسلامي، وضبط تصرف الجماعات، والأقاليم بعضهم مع بعض على وجه يحفظ مصالح الجميع، ورعى مصالح الكلية الإسلامية، وحفظ المصلحة الجامعة عند معارضة المصلحة القاصرة لها، ويسمى هذا بعلم العمران وعلم الاجتماع 13.

هذا ما يتعلق بالمقصد الأعلى من القرآن، وأما المقاصد الأصلية- التي تندرج ضرورة تحت المقصد الأعلى الجامع-فهي حسب استقراء ابن عاشور ثمانية يمكن أن نلخصها في $14:$

إصلاح الاعتقاد. وهذا أعظم سبب لإصلاح الخلق، وتهذيب الأخلاق، والتشريع وهو الأحكام خاصة وعامة، وسياسة الأمة. وفيه صلاح الأمة وحفظ نظامها، والقصص وأخبار الأمم السالفة للتأسي بصالح أحوالمم، والحذر من مساويهم، والتعليم بما يناسب حالة عصر المخاطبين وما يؤهلهم إلى تلقي الشريعة ونشرها وذلك علم الشرائع وعلم الأخبار والمواعظ والإنذار والتحذير والتبشير والإعجاز بالقرآن ليكون آية دالة على صدق الرسول. 
وقد يتساءل المرء عن علاقة هذا العرض المقاصدي بتحديد غرض المفسر من التفسير تتضح هذه الصلة حين يقول ابن عاشور:

"غرض المفسر بيان ما يصل إليه، أو ما يقصده من مراد الله تعالى في كتابه بأتم بيان يحتمله المعنى، ولا يأباه اللفظ من كل ما يوضح المراد من مقاصد القرآن، أو ما يتوقف عليه فهمه أكمل فهم، أو يخدم المقصد تفصيلاً وتفريعاً، مع إقامة الحجة على ذلك إن كان به خفاء أو لتوقع مكابرة من معاند أو جاهل، فلا جرم كان رائد المفسر في ذلك أن يعرف على الإجمال مقاصد القرآن ما جاء لأجله، ويعرف اصطلاحه في إطلاق الألفاظ، وللتتريل

$$
\text { اصطلاح وعادات" (15. }
$$

يتبين لنا من عبارة ابن عاشور هذه أن عمل المفسر وفهمه إنما يجب أن يدور مع المقصد، ومع كل ما يمكن أن يسهم في إيضاحه وجلائه. فالمقصد القرآي هو قطب الرحى في حركة المفسر بمختلف نواحيها ومستوياتا. فبحوث المفسر، وتحليلاته اللغوية، أو البلاغية، أو الكلامية، أو التشريعية، أو الاجتماعية. كل ذلك يجب أن يصب في خدمة المقصد القرآي أساساً. وهذا هو المعيار الذي يجكم عند مطالعة التفاسير ليعرف " مقادير اتصال ما تشتمل عليه بالغاية التي يرمي إليها المفسر، فيوزن بذلك مقدار ما أوفى به من المقصد ومقدار ما بحاوزه" 16.

وانطلاقاً من هذه الرؤية المقاصدية يحدد ابن عاشور موقفه ورأيه في كثير من المسائل والقضايا التي تعد من أصول التفسير ومبادئه، فتكون بمثابة الضابط الذي بكونه علماً إلا لبضع وجوه أحدها: "أن حق التفسير أن يشتمل على بيان أصول التشريع وكلياته فكان بذلك حقيق بأن يسمى علماً. ولكن المفسرين ابتدأوا بتقصي معاني القرآن فطفحت عليهم وحسرت دون كثرتا قواهم، فانصرفوا عن الاشتغال بانتزاع كليات التشريع إلا في مواضع قليلة"17. فإذا تطرق لمسألة التفسير العلمي، أو ما يصح الاستعانة به من العلوم في التفسير، كان المعيار المحكم لديه هو "خدمة المقاصد القرآنية". يذكر ابن عاشور أن من طرائق المفسرين طريقة تقوم على جلب "مسائل علمية من علوم

$$
\begin{aligned}
& 15 \\
& 16 \\
& 17 \text { مرجع سابق، ج } 1 \text { ص ص ص } 13 .
\end{aligned}
$$


لها مناسبة بمقصد الآية: إما على أن بعضها يومئ إليه معنى الآية، ولو بتلويح ما، كما يفسر أحد قوله تعالى: (ومن يؤت الحكمة فقد أوتي خيراً كثيرا) البقرة: 269، فيذكر تقسيم علوم الحكمة ومنافعها. وكذلك أن نأخذ من قوله تعالى: (كيلا يكون دولة بين الأغنياء منكم) الحشر 7، تفاصيل من علم الاقتصاد السياسي وتوزيع الثروة العامة وهلم

وإما على وجه التوفيق بين المعنى القرآني وبين المسائل الصحيحة من العلم حيث يمكن الجمعع، وإما على وجه الاسترواح من الآية، كما يؤخذ من قوله (ويوم نُسيَّر الجبال) الكهف: 47 أن فناء العالم يكون بالزلازل.

وشرط كون ذلك مقبولاً أن يسلك فيه مسلك الإيجاز فلا يجلب إلا الخلاصة من ذلك العلم ولا يصير الاستطراد كالفرض المقصود لئلا يكون كقولم: الشيء بالشيء يذكر "18.

وبعد أن يقرر رأيه في المسألة يعرض آراء العلماء فيها، ويخلص إلى القول: "إن السلف بيّنوا وفصلوا وفرّعوا في علوم عنوا بها ولا يمنعنا ذلك أن نقفي على آثارها في علوم أخرى راجعة لحدمة المقاصد القرآنية أو لبيان سعة العلوم

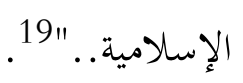

فهو كما نرى لم ينف التفسير العلمي أو ينقضه من أساسه، كما لم يعتمد عليه ويعتبره أساس الهداية القرآنية، وإنما رأى أن القرآن قد أشار إلى علوم أو جاءت هي موافقة له - كعلم طبقات الأرض، والطب، والفلك،- فهذه يكتفي منها بما يمقق المقاصد القرآنية ويخدمها فحسب.

وإذا انتقلنا إلى موضوع أسباب الترول نجد ابن عاشور ينتقد المتقدمين الذين ألفوا في أسباب الترول فاستكثروا منها، وأساءوا بتلقفهم روايات ضعيفة أثبتوها في كتبهم وتوسعوا فيها توسعاً ضيق معاني القرآن العليا. والحق أن "القرآن جاء هادياً إلى ما به صلاح الأمة في أصناف الصلاح، فلا يتوقف نزوله على حدوث الحوادث الداعية إلى 
تشريع الأحكام.."20. فهو "إنما جاء بكليات تشريعية وهذيبية عامة"21، لذا نرى أن ابن عاشور يمحص أسباب الترول فلا يختار منها "إلا ما توقف فهم المقصود من الآية على علمه"22.

وحتى القصص القرآني البديع فإن الغاية منه لا تقتصر على حصول العبرة والموعظة، بل تتجاوز ذلك إلى إرشاد الأمة، وتعريفها بتاريخ من سبقها من الأمم ولكي "تنشئ في المسلمين همة السعي إلى سيادة العالم كما ساده أمم من

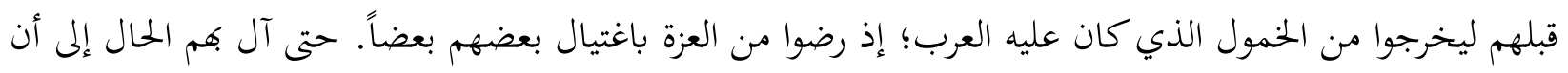
فقدوا عزتم فأصبحوا كالأتباع للفرس والروم"، بالإضافة إلى "فوائد في تاريخ التشريع والحضارة وذلك يفتق أذهان المسلمين للإلمام بفوائد المدنية"23.

ولا يفتأ ابن عاشور مؤكداً حتى عند تناوله لترتيب آي القرآن ومناسباتا على أن"الغرض الأكبر للقرآن هو إصلاح الأمة بأسرها. فإصلاح كفارها بدعوقم إلى الإيمان ونبذ العبادة الضالة، واتباع الإيمان، والإسلام، وإصلاح المؤمنين بتقويم أخلاقهم وتثبيتهم على هداهم وإرشادهم إلى طرق النجاح وتزكية نفوسهم، ولذلك كانت أغراضه مرتبطة بأحوال المجتمع في مدة الدعوة"24.

ووظف ابن عاشور مفهوم"المقاصد"أيضاً في تحليله للنظم القرآي وخصائصه، فكان له في ذلك نظرات حاذقة مبتكرة كقوله مثلاً:" نرى من أعظم الأساليب التي خالف هما القرآن أساليب العرب أنه جاء في نظمه بأسلوب جامع بين مقصديه وهما: مقصد الموعظة ومقصد التشريع، فكان نظمه يمنح بظاهره السامعين ما يحتاجون أن يعلموه، وهو في هذا النوع يشبه خطبهم، وكان في مطاوي معانيه ما يستخرج منه العالم الخبير أحكاماً كثيرة في التشريع والآداب، وقد قال في الكلام على بعضه" وما يعلم تأويله إلا الله والراسخون في العلم" هذا من حيث ما لمعانيه من العموم والإيماء إلى العلل والمقاصد 25.

\begin{tabular}{|c|c|c|}
\hline & مرجع سابق، ج 1 ص 46. & 20 \\
\hline & مرجع سابق، ج 1 ص 50. & 21 \\
\hline & مرجع سابق، ج 1 ص47. & 22 \\
\hline & مرجع سابق، ج 1 ص 67. & 23 \\
\hline & مرجع سابق، ج 1 ص 81. & 4 \\
\hline 116 & مرجع سابق ج 1 ص 115 & 25 \\
\hline
\end{tabular}


ربما كانت الأمثلة السابقة كافية للدلالة على مدى محورية مفهوم" المقاصد" ومركزيته في فكر ابن عاشور لا سيما في مستوى التأصيل التفسيري، أما على المستوى التطبيقي فهذا ما سنتحقق منه ونتبينه في الفصل التالي. ولكن يلزمنا قبل الانتقال إلى ذلك توضيح قضية مهمة، وهي الفرق بين الاتجاه المقاصدي كما تحلى عند ابن عاشور والاتحاهات التفسيرية الأخرى، لا سيما الهدائي منها باعتباره الأكثر قرباً واشتراكاً في كثير من القضايا الرئيسية. بعبارة أخرى، ما سبب إفرادنا لابن عاشور التحاًاً خاصاً وطريقة ميزة ولم ندرجه في سياق التحاهات أخرى تتقاطع معه في كثير؟!.

\section{الاتجاه المقاصدي والاتجاه المدائي: - ائ}

تنبع أهمية هذه القضية - أعني التمييز بين الاتحاه المقاصدي والآخر الهدائي من أمرين اثنين:

الأمر الأول: الصلة المباشرة والاحتكاك القديم بين ابن عاشور والمدرسة الإصلاحية المشرقية مثلة بمحمد عبده ورشيد رضا، ومتابعته لنتاجها الفكري، بما فيها تفسير المنار الذي ينشر تباعاً في مجلة المنار، التي كانت تتداول في تونس بين المجموعات الإصلاحية.

والأمر الثاني: أنّ تفسير ابن عاشور لم يتم حتى بداية الستينات من القرن العشرين، أي أنه سبق بكثير من التجارب الإصلاحية والتجديدية في تفسير القرآن والتي من المفترض أنه اطلع عليها. وهذان الأمران يجعلان التساؤل السابق مشروعاً ومفهوماً.

بداية لا بد من الإشارة إلى أنه بعد تفتيش طويل في أحشاء تفسير ابن عاشور وثناياه لم أعثر على آية إشارة أو ذكر لأي من التفسير الحديثة أو رواد الإصلاح والتجديد أو أحد من معاصريه، اللهم إلا مرات قليلة تضمنت إشارات إلى بعض شيوخه مثل بوعتور أوغيره. وهذا أمر يدعو للتساؤل -بحد ذاته- عن سبب هذا الإغفال أو التجاهل.

قد يصعب تحديد السبب الدقيق لهذه الظاهرة، ولكن نظرة شاملة وكلية إلى أسلوب ابن عاشور قد تساعدنا في تفسير ذلك وتوضيحه إذ يبدو أن ابن عاشور قد أخذ على نفسه مقارعة الأقدمين ومنازلتهم، فكان منه الجري على أساليبهم وعاداتم في التفسير، وإن كان قد إنحاز عنهم من حيث المحتوى والمضمون. 
فنلحظ الأسلوب التقليدي القديم في عرض الآيات وتفسيرها وفي أسلوبه اللغوي الذي يستخدمه، وفي تحاشيه ذكر أي مناسبة أو حدث معاصر، وكأنه يعيش مكعزل عن الواقع المعاصر له. وكأن ابن عاشور تعمد أن يتوفن سنن الأقدمين من حيث الشكل، والأسلوب، والقالب العام للتفسير، حتى يكاد يبدو واحداً من أعلامهم ومبرزيهم، وإن كان قد شق من جهة المضمون والمحتوى طريقاً غير التي سلكوا وابتكر فجاً غير الذي عرفوا.

إذا عدنا إلى الموازنة بين الاتحاهين المقاصدي والهدائي فكيف سيتجلى لنا تمايزها؟! يؤكد الهدائيون وعلى رأسهم رشيد رضا على " أن القرآن الكريم إنما هو مرشد وهاد للناس إلى ما فيه سعادقم في حياتم الدنيا وحياتم الآخرة، فإن هذا هو المقصد الأعلى وما وراءه تابع له أو وسيلة لتحصيله"26 واستخدامه لمفهوم" المقصد الأعلى"هنا يذكرنا بما سبق ذكره، ويؤكد التقارب بين الاتجاهين.

بل إن التحديد الذي وضعه صاحب المنار لطبيعة التفسير ووظيفة المفسر يتشابه كثيراً مع ما اعتبره ابن عاشور غرض المفسر -الذي ذكرناه- إذ يقول رشيد رضا:" فالتفسير الذي يجب على الناس على أنه فرض كفاية هو ذهاب

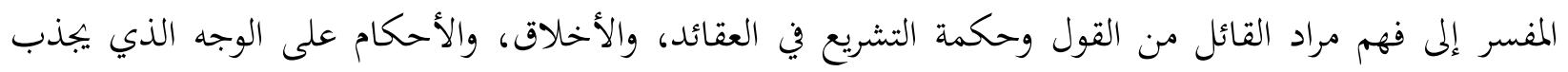
الأرواح، ويسوقها إلى العمل والهداية المودعة في الكلام، ليتحقق فيه معنى قوله:"هدى ورمة" 27.

والموازن بين الاثنين في هاتين النقطتين قد يظن أغما متفقان تمام الاتفاق، وكأفما مقتبسان من مشكاه واحدة، بل قد يثبت ثأثر ابن عاشور الإصلاحية وبالمنار نحديداً، حتى إن لم يشر إليه. وإذا تصور الأمر على هذا النحو، فما مبرر التفريق بين الاتحاهين أو إفراد ابن عاشور بطريقة خاصة وتمييزه عن المدرسة الهدائية؟!.

إن نظرة تحليلية موازنة دقيقة لكلا الاتحاهين ورؤيتهما للتفسير ستثبت أن هناك انعطافاً دقيقاً ومهماً لجهة الهدف والغاية يشكل نقطة الافتراق والتمايز الجلي بينهما. وتتجلى آثار هذا الانعطاف على المستوى التطبيقي واضحة في ما يلحظه أيّ موازن بين"التحرير والتنوير" و"المنار" مثلاً من تمايز واختلاف شاسع من حيث طريقة التفسير، وأسلوبه، وطبيعة الموضوعات المتناولة وغيرها كما سنرى لاحقاً. 
وهذا التحليل الدقيق لنصَّي رشيد رضا وابن عاشور -المحددين غرض التفسير- سيوضح نقطة الاختلاف تلك؛ فصاحب المنار يرى أن المفسر إنما يتخذ فهم مراد القول وحكمة التشريع وسيلة وطريقاً لجذب الأرواح وسوقها إلى العمل والهداية المودعة في الكلام. بينما نجد أن ابن عاشور يعدّ غرض المفسر هو بيان مراد الله وتوضيح مقصده، باعتبار ذلك غاية برأسها، للمفسر أن يستعين لتحقيقها بكل ما يخدم المقاصد القرآنية ويبينها.

إذن، فالهدائيون إنما يتوخون حشد كل ما يستخلصونه من القرآن، من مقاصد وحكم وقواعد تشريعية في شتى المجالات، من أجل الاستفادة منها غوضاً بالمجتمع الإسلامي من حالة السبات والتخلف التي يعيشها، ومعالجة لشئون الحياة كلها معيشية أو مدنية أو سياسية. من هذا المبتغى يمكننا أن نفهم الانشغال المستمر والدائب للهدائيين في تفاسيرهم بالقضايا الواقعية التي تشغل حاضرهم محاولين كشف الهدى القرآي فيها، باعتبار القرآن دستور الأمة ومرشدها في شتى شئوفا وقضاياها فقد" كانوا في تفاسيرهم واقعيين تطبيقيين، كما كانوا في واقعيتهم وتطبيقاتم هدائين مجددين"28.

بينما نجد أن ابن عاشور يسلك الابحاه المعاكس ويقصد غاية أخرى تتجلى في بيان المقاصد القرآنية وبحليتها بتوظيف مختلف الأساليب والوسائل والعلوم (من لغة وبلاغة، ونخو، وأصول فقه، وعمران، واجتماع، وسياسة) في الكشف عن مختلف مستويات المقاصد وأنواعها (كلية، جزئية، فردية، أو جماعية أو عمرانية، تشريعية اعتقادية أو بيانية...) وهذا يفسر لنا ندرة إشارته إلى القضايا والمشكلات يعيشها المجتمع الإسلامي في عصره، بل قلما يذكر أو يتناول المسائل العلمية والقضايا المثيرة للجدل التي ظهرت مع الإصلاح والتجديد، وهذا ما سؤخذ عليه في ما بعد قد يقول قائل: أليست المقاصد التي يتوخى ابن عاشور إظهارها وبياها هي ما ذكره من هداية الأمة وإصلاحها فردياً وجماعياً وعمرانياً، فحاصل الاتحاهين - إذن - متفق في إظهار هداية الله للخلق وإصلاحهم في شتى مناحي حياتم. أقول: صحيح أن المقاصد- كما حددها ابن عاشور نفسه- لا تخرج عن هداية الأمة وإرشادها إلى حلول مشكلاتما، إلا أن ابن عاشور يقصر مهمة المفسر على تحديد مقاصد القرآن كما تتجلى في كلام الله تعالى، دون أن يتجاوز ذلك إلى النظر في المشكلات المعاصرة على ضوء هَدي القرآن ومقاصده، فتلك قضية أخرى لا تدخل في التفسير كما يرى أو يراها ابن عاشور. في حين نجد الهدائيين يتجاوزون تحديد مقاصد القرآن وهداياته إلى محاولة 
تفعيلها وتطبيقها في واقع المسلمين عن طريق عرض مشكلاقم الواقعية وقضاياهم المعصرة، ومولة النظر في حلوها على ضوء ما يرونه مناسباً من مقاصد القرآن، وهديه، وكلياته التشريعية.

ويبدو أن نظرة ابن عاشور إلى وظيفة التفسير ودوره في الواقع كانت لا تزال تحمل كثيراً من الآثار التقليدية القديمة، وإن حاول أن يجدد على صعيد المحتوى والمضمون. وهكذا يظهر أن مدرسة الهدائيين كانت متقدمة على الاتحاه المقاصدي من هذه الزاوية، وإن لم تبلغ شأوه في تحليه مقاصد القرآن في مختلف مستوياتما وتفصيلاتما على النحو الذي ظهر في "التحرير والتنوير" وكما سنبين طرفاً منه في ما يأتي:

\section{المبحث الثاني: الاتجاه المقاصدي (المستوى التطبيقي):}

إذا كنا قد تناولنا في ماسبق المستوى التنظيري والتأصيلي للاتجاه المقاصدي عند ابن عاشور، فمن اللازم أيضاً تناول المستوى التطبيقي لهذا الاتحاه. وذلك بعرض طرف من طريقة ابن عاشور في تناول مفهوم"المقاصد"وتوظيفه في تفسير القرآن. يمكن تحديد طريقة ابن عاشور في توظيف مفهوم"المقاصد"في شكلين:

الأول: تقصيد النصوص والأحكام، والثاني: الاستدلال بالمقاصد على الدلالات والأحكام.

تقصيد النصوص والأحكام:

يتجه الذهن في "التقصيد" إلى ضبط نوعين من المقاصد الشرعية: الأول مقاصد الشارع من خطابه، والثاني: مقاصده من أحكامه. يروم الفهم في هذا المستوى إلى إفراغ الباحث جهده العلمي في استجلاء الإرادة الشرعية من النصوص والأحكام.

وهذا المصطلح "التقصيد" مستعار من الإلمام الشاطبي، حيث يلتزم في نظره كلاً من الناظر في القرآن، والمفسر له، والمتكلم عليه، أن يكون على بال من " أن ما يقوله تقصيد منه للمتكلم، والقرآن كلام الله، فهو يقول بلسان بيانه هذا مراد الله من هذا الكلام"29. وفي ما يلي بعض الشواهد والأمثلة على هذا التقصيد من تفسير ابن عاشور: 
رخصة التيمم: قال تعالى: "وإن كنتم جنباً فاطهروا.. فتيموا صعيداً طيبا"30. يدل النص على أنه عند افتقاد الماء يرخص في التيمم، والمقصد الشرعي من حكم الرخصة بالنسبة لعادم الماء أو عند العجز هو التنبيه على عظم قدر الصلاة، لأغها من قبيل المقاصد الشرعية لذلك تأكد وجوب التطهر لها بوسيلة الماء، فإن انعدم التجأ إلى وسيلة التيمم التي أقامها الشارع مقام الطهارة. والمقصد من ذلك ألا يستشعر المسلم أنه يناجي ربه بدون تطهر، وحتى لا تفوته نية التطهر للصلاة، فلا يفوته ذلك المعنى المنتقل به من طهارة الظاهر إلى طهارة الباطن، وحتى لا يظن أن أمر الطهارة هين، وفي إقامة ذلك العمل مقام الطهارة تذكير مستمر بها حتى لا ينسى العود غليها عند زوال ما منعه منها 31. قيام الكعبة: قال تعالى: "جعل الله الكعبة البيت الحرام قياماً للناس"32. والمقصد من جعل الشارع الكعبة قياماً للناس هو تكوين أمة أصلية من ذرية إسماعيل ها كامل الصفات التي تؤهلها لتلقي الشريعة الخاتمة.

وجماع هذه الصفات: جودة الأذهان، وقوة الحوافظ، وبساطة الحضارة، والتشريع، والبعد عن الاختلاط ببقية الأمم 33

في قوله تعالى: "قال كم لبثتم في الأرض عدد سنين. قالوا لبثنا يوماً أو بعض يوم فسئل العادين. قال: إن لبثتم

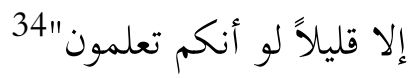

قال ابن عاشور: ولم يعرج المفسرون على تبيين المقصد من سؤالهم وإجابتهم عنه وتعقيبه بما يقره في الظاهر. والذي لاح لي في ذلك أن إيقافهم على ضلال اعتقادهم الماضي جيء به في قالب السؤال عن مدة مكثهم في الأرض كناية عن ثبوت خروجهم من الأرض أحياءً وهو ما كانوا ينكرونه. وكناية عن خطأ استدلالمم على إبطال البعث باستحالة رجوع الحياة إلى عظام ورفات. وهي حالة لا تقتضي مدة قرن واحد فكيف وقد أعيدت إليهم الحياة

\begin{tabular}{|c|c|}
\hline المائدة الآية (6). & 30 \\
\hline التحرير والتنوير، 126/6. & 31 \\
\hline المائدة (6). & 32 \\
\hline التحرير والتنوير. & 33 \\
\hline المؤمنون، 112-114. & 34 \\
\hline
\end{tabular}


بعد أن بقوا قروناً كثيرة. فذلك أدل وأظهر في سعة القدرة الإلهية وأدخل في إبطال شبهتهم إذ قد تبين بطلاهما في ما هو أكثر مما قدروه من علة استحالة عود الحياة إليهم" 35.

قوله تعالى:" وآتوا النساء صدقاتن نحلة..."36. فالمقصود من توجيه الخطاب في الآية إلى الأزواج هو عدم

تذرعهم بضعف النساء وحيائهن في سبيل غمط حقوقهن التي منها مهورهن 37.

قال تعالى: "أتبنون بكل ريع آية تعبثون. وتتخذون مصانع لعلكم تخلدون. وإذا بطشتم بطشتم جبارين 38. بعد

ذكره الأعمال النافعة من بناء ومصانع يقول ابن عاشور: "فإذا أهمل إرضاء الله بها واتخذت للرياء والغرور بالعظمة

وكانوا معرضين عن التوحيد وعن عبادة الله، انقلبت عظمة دنيوية محضة لا ينظر فيها إلى جانب النفع ولا تحث الناس

على الإقتداء في تأسيس أمثالها وقصاراها التمدح بما وجدوه منها فصار وجودها شبيهاً بالعبث لأهما خلت عن روح المقاصد الحسنة فلا عبرة عند الله هها لأن الله خلق هذا العالم ليكون مظهر عبادته وطاعته 39.

ثم يتابع ابن عاشور قائلاً "ولما صار أثر البناء شاغلاً عن المقصد النافع للحياة في الآخرة نزل فعلهم المفضي إلى العبث مترلة الفعل الذي أريد منه العبث عند الشروع فيه، فأنكر عليهم البناء بإدخال همزة الإنكار على فعل" تبنون "..." ثم يستطرد في بيان وجه دلالة الآية على هذا المقصد لغوياً وبلاغياً.

$$
\text { الوفاء بالعقود. قال تعالى:" يا أيها الذين آمنوا أوفوا بالعقود. .)مب. }
$$

لما كان المقصد الشرعي من شرع العقود سد حاجة الأمة اعتباراً للمناسب الحاجي، تعين في هذا النص وجوب

إيفاء العاقد بعقده 41.

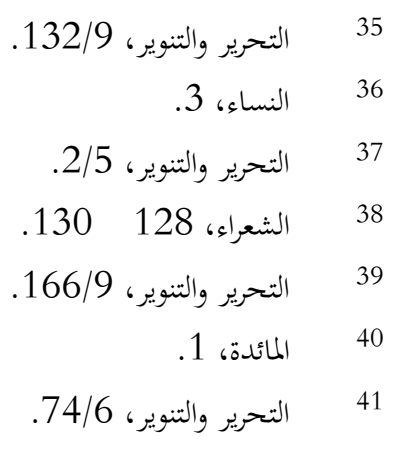


قال تعالى: (وما يستوي البحران هذا عذب فرات سائغ شرابه وهذا ملح أجاج ومن كل تأكلون لحماً طرياً وتستخرجون حلية تلبسوفا وترى الفلك فيه مواخر لتبتغوا من فضله ولعلكم تشكرون)22. يقول ابن عاشور:" وتقديم الظرف في قوله:"فيه مواخر على عكس آية سورة النحل، لأن الآية مسوقة مساق الاستدلال على دقيق صنع الله في المخلوقات، وأدمج فيه الامتنان بقوله "يأكلون... وتستخرجون حلية "، وقوله "لتبتغوا من فضله" فكان المقصد الأول من سياقها الاستدلال على عظيم الصنع فهو الأهم هنا. ولما كان طفو الفلك على الماء حتى لا يغرق فيه أظهر في الاستدلال على عظيم الصنع من الذي ذكر من النعمة والامتنان قدم ما يدل عليه وهو الظرفية في البحر. والمخر في البحر آية صنع الله أيضاً بخلق ومائل ذلك والإلهام له، إلا أن خطور السفر من ذلك الوصف أو ما يتبادل إلى الفهم فأخر هنا لأنه من مستتبعات الغرض لا من مقصده، فهو يستتبع نعمة تيسير الأسفار لقطع المسافات التي لو قطعت لو بسير القوافل لطالت مدة الأسفار 43.

قال تعالى:" قل إنما أنا منذر وما من إله إلا الله الواحد القهار. رب السموات والأرض وما بينهما العزيز الغفار "44. والمقصود من وصف "الغفار" هنا استدعاء المشركين إلى التوحيد بعد تمديدهم بمفاد وصف "القهار" لكي لا ييأسوا من قبول التوبة بسبب كثرة ما سبق إليهم من الوعيد جرياً على عادة القرآن في تعقيب الترهيب بالترغيب والعكس 45.

واضح مما سبق أهمية مفهوم "المقاصد" عند ابن عاشور، إذ لا يقتصر تقصيده على الأحكام الشرعية التكليفية بل يتجاوزها إلى نصوص الترغيب والترهيب والقصص والتحليل البلاغي واللغوي للآيات القرآنية.

الاستدلال على الدلالات والأحكام الشرعية

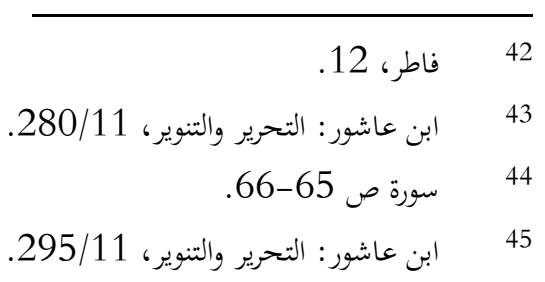


يعكس الاستدلال في صورة متكاملة الغاية المنهجية للفكر، ففيه التنظيم المؤسس على قراءات نظرية ووسائل منهجية وفيه التركيب لأن كل استدلال يتحتم توفره على ثلاثة عناصر هي مقدمة يستدل بها، ونتيجة لازمة عن تلك تلك المقدمة، وعلامة منطقية بين المقدمة والنتيجة. وتستند مقدمات الاستدلال هنا على مقاصده من خطابه أو مقاصده من أحكامه. فمن ذلك:

\section{قال تعالى: (لن ينال الله لحومها ولا دماؤها.ذ..)64}

يرى ابن عاشور أن "الآية تومئ إلى أن المقصد الشرعي من وسيلتي إراقة الدماء وتقطيع اللحوم هو انتفاع

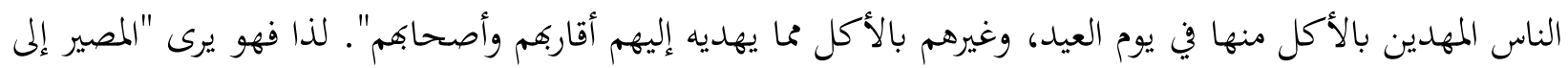
كلا الحالين من البيع والتصبير لما فضل عن حاجة الناس في أيام الحج ليتنفع بها المحتاجون في عامهم، وهذا أوفق بمقصد الشارع تجنباً لإضاعة ما فضل منها رعياً لمقصد الشريعة من نفع المحتاج وحفظ الأموال، مع عدم تعطيل النحر والذبح للقدر المحتاج إليها منها، المشار إليه بقوله تعالى:" فاذكروا اسم الله عليهم صواف...." جمعاً بين المقاصد الشرعية

قال تعالى: (ألم تعلم أن الله على كل شيء قدير. ألم تعلم أن الله له ملك السموات والأرض وما لكم من دون الله من ولي ولا نصير..) 48 يقول ابن عاشور في استدلاله على المخاطب في "تعلم": "والخطاب في تعلم ليس مراداً منه ظاهره الواحد وهو النبي صلى الله عليه وسلم، بل هو إما خطاب لغير معين خارج على طريقة المجاز بتشبيه من ليس حاضراً للخطاب وهو الغائب مترلة المخاطب في كونه بحيث يصير مخاطباً لشهرة هذا الأمر، والمقصد من ذلك ليعم كل مخاطب صالح له.... وإما مراده ظاهره وهو الواحد في كون المخاطب هو النبي صلى الله عليه وسلم لكن المقصود منه المسلمون فينتقل من خطاب النبي صلى الله عليه وسلم إلى مخاطبة أمته انتقالاً كنائياً. فتارة يراد من الخاطب توجه الخطاب إليه وتارة يقصد توجه المضمون لأمته.... وها هنا لا يصلح توجه المضمون للرسول لأنه لا يقرر

46
48
47
47


على الاعتراف بأن الله على كل شيء قدير، فضلاً عن أن ينكر عنه، وإنما التقرير للأمة والمقصد من تلك الكناية التعريض باليهود

قال تعالى: "واللاتي تخافون نشوزهن..."50. لخص ابن عاشور حاصل رأيه في المسألة فقال: "يجوز لولاة الأمور إذا علموا أن الأزواج لا يحسنون وضع العقوبات الشرعية مواضعها، ولا الوقوف عند حدودها، أن يضربوا على أيديهم استعمال هذه العقوبة، ويعلنوا أن من ضرب امرأته عوقب كي لا يتفاقم أمر الإضرار بين الأزواج لاسيما عند ضعف

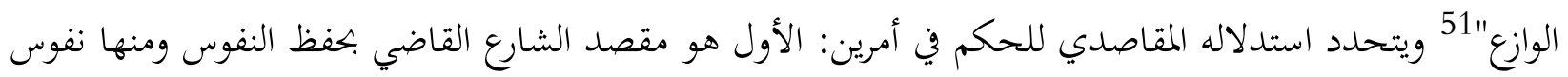
النساء من كل اعتداء نفسي أو جسدي، والثاني هو الأول في قواعد الشرعية عدم قضاء أحد بنفسه إلا لضرورة. قال تعالى: "وإذ قال موسى لقومه يا قوم إنكم ظلمتم أنفسكم باتخاذكم العجل فتوبوا إلى بارئكم فاقتلوا أنفسكم. 52 "قال ابن عاشور: "في هذا تشرح حكم لا يكون مثله إلاعن وحي لا عن اجتهاد وإن جاز الاجتهاد للأنبياء فإن هذا حكم مخالف لقاعدة حفظ النفوس التي اتفق عليها شرائع الله، فهو يدل على أنه كلفهم بقتل أنفسهم قتلاً حقيقة"53.

قال تعالى: "يجعلون أصابعهم في آذافم من الصواعق... ولو شاء الله لذهب بسمعهم وأبصارهم..."54 يتكلم ابن عاشور عن معنى "لو" هنا ووظيفتها في كون: "ليس المقصود من اجتلاب "لو" في هذا الشرط إفادة ما تقتضيه "لو" من الامتناع لأنه ليس المقصود الإعلام بقدرة الله على ذلك، / بل المقصود إفادة لازم الامتناع وهو أن أسباب إذهاب البرق والرعد أبصارهم الواقعين في التمثيل متوفرة، وهي كفران النعمة الحاصلة منهما، إذ أغما رزقوها للتبصر في الآيات الكونية وسماع الآيات الشرعية فلما اعرضوا عن الأمرين كانوا أحرياء بسلب النعمة، إلا أن الله لم يشأ ذلك

\begin{tabular}{|c|c|}
\hline ابن عاشور: التحرير والتنوير، 663/1. & 49 \\
\hline النساء، 34. & 50 \\
\hline ابن عاشور: التحرير والتنوير، 37/5. & $\$ 1$ \\
\hline البقرة 5. & 52 \\
\hline ابن عاشور: التحرير والتنوير، 502/1. & \\
\hline البقرة، 20. & \\
\hline
\end{tabular}


إمهالاً لمم، وإقامة للحجة عليهم فكانت"لو" مستعملة بحازاً مرسلاً في ججرد إظهاراً لتوفر الأسباب لولا وجود

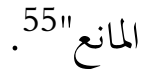

هذه بعض الشواهد الدالة على توظيف ابن عاشور مفهوم "لمقاصد" في الاستدلال سواء للأحكام الشرعية،

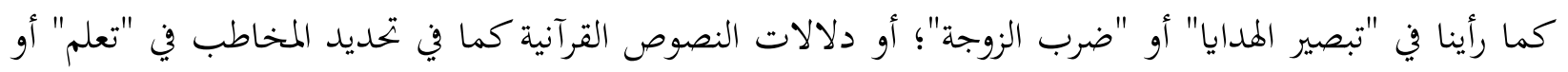

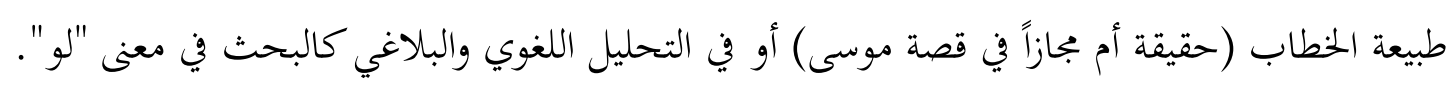

\section{المبحث الثالث: ملامح من منهج أبي عاشور في تفسيره:}

لابد لنا وقبل أن نختم عن ابن عاشور واتجاهه المقاصدي في التفسير أن نشير إلى بعض ملامح منهجه، الذي توصل به إلى تحقيق غايته، وأهدافه ومقاصده. وإضافة إلى ما سبق ذكره من بعض النقان النقاط المنهجية في سياق التأصيل

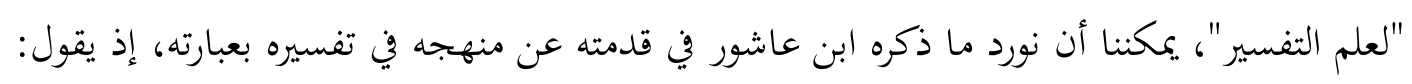

"وإن معاني القرآن ومقاصده ذات أفانين كثيرة بعيدة المدى مترامية الأطراف موزعة على آياته؛ فالأحكام مبينة

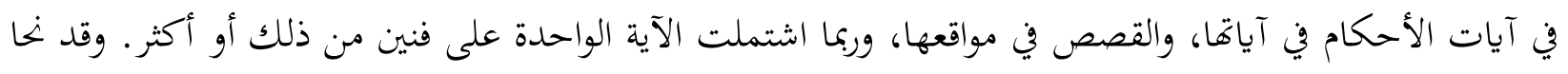

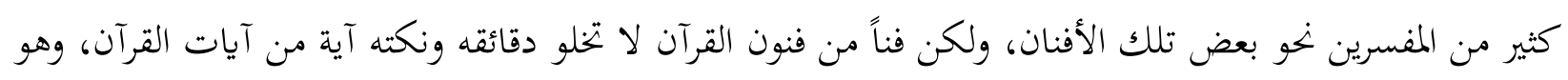

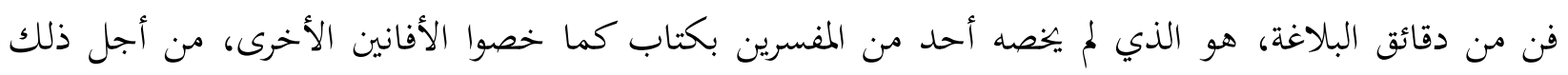

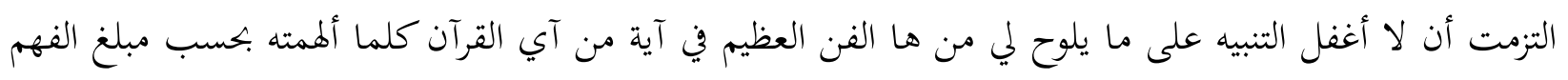
وطاقة التدبر. وقد اهتممت في تفسيري هذا بييان وجوه الإعجاز ونكت البلاغة العربية وأساليب الاستعمال. واهتممت أيضاً بييان تناسب وقد اهند

اتصال الآي بعضها ببعض، وهو مترع جليل قد عني به فخر الدين الرازي وألف فيه برهان الدين البقاعي كتابه

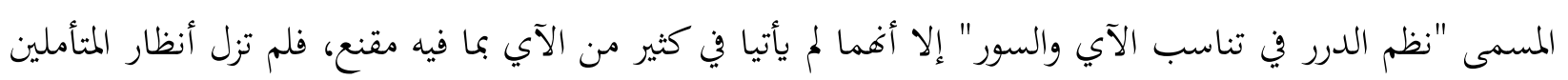

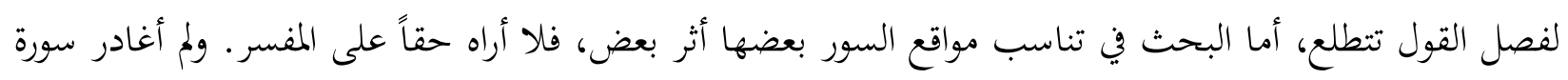


إلا بينت ما أحيط به من أغراضها لئلا يكون الناظر في تفسير القرآن مقصوراً على بيان مفرداته ومعاني جمله، كأفا فقر متفرقة تصرفه عن روعة انسجامه وتحجب عنه روائع جماله. واهتممت ببيان معاني المفردات في اللغة العربية بضبط وتحقيق مما خلت عن ضبط كثير منه قواميس اللغة. وعسى أن يجد فيه المطالع تحقيق مراده، ويتناول منه فوائد ونكتاً على قدر استعداده..."

ولابد أن نضيف إلى أنه يعتمد في الفقه والأحكام على المذهب المالكي بصورة رئيسية مع تعرضه المذاهب الفقهية الأخرى، ولأقوال الصحابة والتابعين. وهو في كل ذلك يحقق الأقوال ويرجح ويقارن دون أن يتحجر باتباع مذهب معين أو كرة محددة، بل يسير مع أي رأي يتفق ومنهجه التشريعي ورؤيته المقاصدية، وإن لاحظنا أحياناً غلبة واضحة للمذهب المالكي باعتباره منبع هذه الرؤية ومؤصلها 57.

قد يرى البعض في ما نقلناه عن ابن عاشور في تحديده منهجه، وفي تفسيره عموماً أن ابن عاشور إنما يعبر بما ذكره وطبّه في تفسيره عن انتمائه إلى المدرسة البيانية الأدبية في تفسير القرآن ولا أدل على ذلك من اهتمامه البالغ بعلم البيان والبديع، والوقوف على النكت البلاغية، وإبراز ظواهر الإعجاز القرآي !!58.5

يجدر بنا في هذا السياق، ولإزالة هذا اللبس، أن نشير إلى ظاهرة غريبة تتعلق بتفسير ابن عاشور. وهي أن الناظر في اهتماماته اللغوية يحسب أنه منن البلاغيين الأدباء، والناظر في تحليلاته الاجتماعية والسياسية والتاريخية يرى أنه من رؤوس الهدائين وأعلامهم، بينما يرجح آخر أنه من الفقهاء المجددين مما يراه من تحقيقات فقهية وأصولية واجتهادات حاذقة.

وابن عاشور - في حقيقته- بين هؤلاء وأولئك جامع "موفق"، وترجيح انتساه إلى إحدى المدارس التفسيرية تلك ليس بأولى من ترجيح انتسابه إلى أخرى. فهو يرى -كما نقلناه سابقاً: "أن معاني القرآن ومقاصده ذات أفانين كثيرة بعيدة المدىى مترامية الأطراف". لذا فقد جاء تفسيره على وفق هذه المقاصد متعدد الجوانب مختلف تهن

$$
\begin{aligned}
& 56 \text { م } 57
\end{aligned}
$$

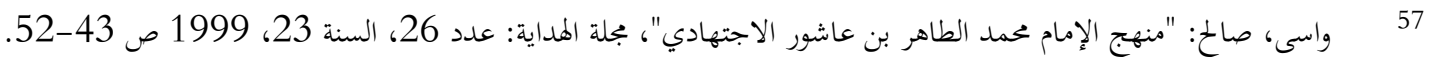

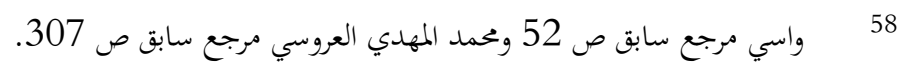


الاهتمامات، لا على نخو تجميعي تقليدي متناثر، وإنما وفق نظرية ونسق محدد اختاره ابن عاشور ناظماً لتفسيره وموحداً لاهتماماته، ألا وهو النسق المقصدي أو "النظرية المقاصدية". من هنا يمكن أن نفهم مثلاً أن انشغال ابن عاشور بعلوم البلاغة والبيان وغيرها، غنما كان بالمقدار الذي يتوافق مع نظريته المقاصدية ويخدمها، وليست غاية بحد ذاتا ومقصداً مستقلاً أراد تحقيقه كما هو الحال عند أصحاب المدرسة الأدبية أو البلاغية والكلام ذاته ينطبق على مختلف اهتمامات ابن عاشور العلمية في تفسيره.

الحلاصة:

بهد هذا الطواف السريعة في حياة ابن عاشور وفكره وتفسيره، وهذا التحليل المنهجي لاتحاه ابن عاشور وطريقته التفسيرية، يمكنني أن أسجل - على سبيل الخلاصة - بعض النتائج الرئيسية هنا:

1-يعد ابن عاشور أحد أعلام الإصلاحيين الذين اتخذوا التجديد والاجتهاد والإصلاح منهجاً وسبيلاً في فكرهم وحياقم. وماتفسيره إلا أحد نتاجات هذه الحركة التجديدية.

2-لقد انفرد ابن عاشور باتحاه ميز وطريقة خاصة في التفسير، دعوها "الطريقة المقاصدية" أو الاتحاه المقاصدي" في التفسير. وتتجلى المقولة الأساسي لهذا الاتحاه في: توظيف جميع العلوم والوسائل والأدوات المعرفية المتوافرة في الكشف عن المقاصد القرآنية وإظهارها على أحسن وجه، تلك المقاصد المتمثلة في إصلاح الفرد والمجتمع والأمة وهدايتهم.

3-إن النزعة النقدية والاتحاه المقاصدي لدى ابن عاشور لم ينشأ من فراغ وإنما كانا حصيلة عوامل كثيرة كان منها: انخراطه المبكر في الحركة الإصلاحية المشرقية والمغربية وتشربه النزعة المقاصدية الكامنة في مهبه المالكي، والتي طورها الشاطبي. الأمر الذي دفعه إلى تأسيس أول نظرية مقاصدية متكاملة بعد الشاطبي والدعوة إلى إنشاء علم مستقل يدعى علم مقاصد الشريعة. 
4-يتميز اتجاه ابن عاشور المقاصدي عن غيره من الاتجاهات التفسيرية من جوانب متعددة. يأتي على رأسها رؤيته لوظيفة التفسير ومهمة المفسر. وهو إن اتفق م الاتحاه الهدائي مثلاً من حيث النظرة إلى القرآن الكريم ودوره في حياة المسلمين وحل مشكلاقمم الواقعية، ولكنه يختلف معهم من حيث وظيفة التفسير المقتصرة على بتحلية المقاصد القرآنية وإيضاحها، باعتبار أن ذلك هو أول طريق للإصلاح.

5-احتل مفهوم "المقاصد مكانة مركزية في فكر ابن عاشور عموماً وفي تفسيره خصوصاً. واتخذت وظيفته في التفسير أشكالاً عدة منها: التأصيل التفسيري، تقصيد النصوص والأحكام، الاستدلال بالمقاصد على الأحكام والدلالات.

6-لقد اختار ابن عاشور منهجاً ذا أبعاد وجوانب متنوعة، ليتناسب ذلك م نظريته المقاصدية التي تؤكد على تعداد المقاصد القرآنية وتنوعها، وضرورة تناول القرآن من مختلف جوانبه، وبمختلف الوسائل حتى تتبين جميع مقاصده على حد سواء.

ختاماً؛ لا يسعنا إلا الاعتراف بأصالة الشيخ محمد الطاهر ابن عاشور ونبوغه في مختلف نواحي العلوم الإسلامية، الأمر الذي بحلى في تفسيره الذي جاء موسوعة علمية كبيرة حوت مختلف العلوم والمعارف ودلت على سعة ثقافته وأصالة فكره.

هذا إلى جانب الدور الإصلاحي التجديدي الذي أسهم به في المغرب العربي، حتى أصبح مدرسة مستقلة لها رجالها وتلاميذها، مدرسة أصبحت تدعى "مدرسة مقاصد الشريعة". كما يجب القول بأن هذه الدراسة الموجزة ليست إلا خطوة صغيرة في سبيل تحليل طريقة ابن عاشور ومنهجه التفسيري، أو في سبيل دراسة وتحليل أيّ من رجال الإصلاح والتجديد الذين ظهروا في عصرنا الحديث. وهي لذلك بحاجة إلى كثير من التعميق والتوسيع الذي حال دونه طبيعة الدراسة وضيق الزمن. والله الموفق. 